\title{
Pathology of immune reconstitution inflammatory syndrome in multiple sclerosis with natalizumab-associated progressive multifocal leukoencephalopathy
}

\author{
Imke Metz • Ernst-Wilhelm Radue • Agustin Oterino • Tania Kümpfel • \\ Heinz Wiendl · Sven Schippling • Jens Kuhle • Mohammad Ali Sahraian • \\ Francoise Gray • Veronika Jakl • Darius Häusler • Wolfgang Brück
}

Received: 17 September 2011/Revised: 16 October 2011/Accepted: 24 October 2011/Published online: 6 November 2011

(C) The Author(s) 2011. This article is published with open access at Springerlink.com

\begin{abstract}
Natalizumab is an approved medication for highly active multiple sclerosis (MS). Progressive multifocal leukoencephalopathy (PML) may occur as a severe side effect of this drug. Here, we describe pathological and radiological characteristics of immune reconstitution inflammatory syndrome (IRIS), which occurs in natalizumab-associated PML after the cessation of therapy, and we differentiate it from ongoing PML. Brain biopsy tissue and MRI scans from five MS patients with natalizumab-associated PML were analyzed and their histology compared with non-MS PML. Histology showed an extensive CD8-dominated T cell infiltrate and numerous macrophages within lesions, and in nondemyelinated white and grey matter, in four out of five cases. Few or no virally infected cells were found. This was indicative of IRIS as known from HIV patients with PML. Outstandingly
\end{abstract}

I. Metz $(\bowtie) \cdot$ D. Häusler · W. Brück

Department of Neuropathology, University Medical Center,

Georg August University Göttingen, Robert-Koch-Str. 40,

37075 Göttingen, Germany

e-mail: imetz@gwdg.de

E.-W. Radue

Medical Image Analysis Center (MIAC),

University Hospital Basel, Basel, Switzerland

\section{A. Oterino}

Service of Neurology, University Hospital "Marqués de

Valdecilla", Santander, Spain

T. Kümpfel

Institute for Clinical Neuroimmunology,

Ludwig-Maximilians-University, Munich, Germany

H. Wiendl

Department of Neurology-Inflammatory Disorders of the Nervous System and Neurooncology, Westfälische Wilhelms Universität, Münster, Germany high numbers of plasma cells were present as compared to non-MS PML and typical MS lesions. MRI was compatible with IRIS, revealing enlarging lesions with a band-like or speckled contrast enhancement either at the lesion edge or within lesions. Only the fifth patient showed typical PML pathology, with low inflammation and high numbers of virally infected cells. This patient showed a similar interval between drug withdrawal and biopsy (3.5 months) to the rest of the cohort (range 2.5-4 months). MRI could not differentiate between PML-associated IRIS and ongoing PML. We describe in detail the histopathology of IRIS in natalizumabassociated PML. PML-IRIS, ongoing PML infection, and MS exacerbation may be impossible to discern clinically alone. MRI may provide some clues for distinguishing different pathologies that can be differentiated histologically. In our

\author{
S. Schippling \\ Institute for Neuroimmunology and Clinical MS Research \\ (inims), University Medical Center Eppendorf, Hamburg, \\ Germany \\ J. Kuhle \\ Neurology and Clinical Neuroimmunology, University Hospital, \\ University of Basel, Basel, Switzerland
}

\section{A. Sahraian}

Sina MS Center, Sina Hospital, Tehran University of Medical

Sciences, Tehran, Iran

F. Gray

Department of Pathology, APHP Hôpital Lariboisière,

Université Paris 7, Paris, France

V. Jakl

Department of Neurology, Ludwig-Maximilians-University, Munich, Germany 
individual cases, biopsy helped to clarify diagnoses in natalizumab-associated PML.

Keywords IRIS - Natalizumab $\cdot$ PML $\cdot$ MS · Pathology $\cdot$ MRI

\section{Introduction}

Natalizumab is a humanized anti-alpha4-integrin antibody. Binding of the antibody on T cells, B cells, and monocytes inhibits the entry of inflammatory cells into the brain [4]. In phase III studies, natalizumab has been shown to significantly reduce the relapse rate as well as disability progression, and was approved as therapy for active relapsing-remitting multiple sclerosis (MS) [17]. However, so far, 170 cases (June 2011) of therapy-associated progressive multifocal leukoencephalopathy (PML) have been documented [24].

PML is an opportunistic viral brain disease caused by a reactivation of latent JC virus (JCV) infection. This infection is increasingly recognized in patients treated with monoclonal antibody therapies [1, 2]. Histologically, JCV leads to a demyelinating disease with ground glass oligodendrocytes (oligodendrocytes with viral nuclear inclusions), bizarre astrocytes, and a low inflammatory infiltrate. Magnetic resonance imaging (MRI) typically presents with focal or multifocal high signal abnormalities on T2-weighted images, which become confluent and larger with progression of the disease. The lesions are diffuse and mainly located in subcortical areas that tend to involve U fibers. In general, they do not enhance after contrast injection [22].

The overall PML risk for MS patients treated with natalizumab is about $1: 1,000$ [28]. Patients with preceding immunosuppression, therapy duration $>2$ years, and presence of anti-JCV antibodies have the highest risk of developing PML (8.3:1,000; [20]). MRI shows new lesions typically in areas not previously affected by MS that may present gadolinium enhancement [2]. The only known effective therapy for PML is reconstituting the immune system. Natalizumab therapy is therefore stopped. Elimination of the antibody can be accelerated by plasmapheresis or immunoadsorption [8, 27]. However, patients regularly develop an exacerbation of symptoms or enlarging lesions or increased gadolinium enhancement on MRI, indicative of immune reconstitution inflammatory syndrome (IRIS) [2].

IRIS describes a clinical worsening in patients with opportunistic infections due to recovery of the immune system. This syndrome is known from HIV patients receiving highly active antiretroviral therapy (HAART). The histopathological hallmark in HIV patients with PML is an inflammatory lesion with a dense $\mathrm{T}$ cell infiltrate dominated by $\mathrm{CD} 8+$ cells and numerous macrophages
$[15,19,25]$. Within lesions, the JC virus may be detected, but it may also be cleared [25].

We describe here the histological and MRI characteristics of five MS patients with natalizumab-associated PML, and compare histological results with non-MS PML cases.

\section{Patients and methods}

Patients

MS patients with natalizumab-associated PML

We investigated biopsy tissue from five MS patients who had been treated with natalizumab for different periods of time ranging from 13 to 40 infusions. In cases 1 [21] and 5, natalizumab-associated PML was diagnosed before biopsy by JCV polymerase chain reaction (PCR) in cerebrospinal fluid (CSF). Patient 1 presented three months after PML diagnosis and $>8$ weeks after the last plasma exchange (PLEX)/immunoadsorption (IA) with an enlarging, faintly gadolinium-enhancing lesion. He was clinically stable at this time. Biopsy was performed to distinguish between reemerging PML, late development of PML-associated IRIS, or a rebound of MS after cessation of natalizumab treatment. Patient 5 was biopsied 3.5 months after the last natalizumab infusion because of continuous clinical progression. This patient had received immunosuppressive therapy with cyclosporin (serum concentrations $50-100 \mathrm{ng} / \mathrm{ml}$ started two months before biopsy) as well as repeated intravenous methylprednisolone $(6 \times 500-1,000 \mathrm{mg}$ for five days, last infusion four days before biopsy) to combat suspected IRIS. Gadolinium-enhancing as well as nonenhancing lesions were present on MRI. Biopsy was performed to distinguish between PML-associated IRIS or ongoing PML. PML was suspected in cases $2-4$, but CSF PCR for JCV was initially negative. Thus, biopsies were performed to diagnose PML. Results received after biopsy showed low CSF copy numbers in case 3 , but remained negative for patients 2 and 4 . Biopsies had been performed at different centers for diagnostic reasons and were sent to the Department of Neuropathology in Göttingen for a second opinion. Specimens were sent from Würzburg (Germany), Santander (Spain), Hamburg (Germany), Basel (Switzerland), and Munich (Germany). Stereotactically guided needle biopsies were performed in three patients (patients 1, 4, and 5) and open biopsies in two patients ( 2 and 3 ). We detected single JCV-positive cells by either immunohistochemistry (IHC) or in situ hybridization (ISH) in two cases (cases $2+3$ ). JCV infection in case 4 was assumed due to positive JCV PCR from brain tissue $\left(9.31 \times 10^{4} \mathrm{Geq} / \mathrm{ml}, \mathrm{H}\right.$. H. Hirsch, Institute for Medical Microbiology, University of Basel; confirmation by E. O. Major, NIH, Bethesda, MD, USA). Sequencing 
revealed a rearranged, noncoding control region, as is typical for PML. Moreover, an intrathecal JCV-specific antibody production was found, which argues in favor of the diagnosis of PML. The characteristics of this patient have been published without a detailed histological analysis [11]. IHC in case 5 showed numerous JCV-infected cells. Clinical and laboratory data are summarized in Table 1. Patients gave written informed consent for participation in this study.

Follow-up of patients showed clinical stabilization in patients 1 and 3. The Expanded Disability Status Score (EDSS) in patient 1 was 4.0 and in patient 3 was 8.5 at biopsy and last follow-up. Patients 2 and 4 showed clinical improvement after biopsy (patient 2: EDSS at biopsy 8.0, EDSS at last follow-up 6.5; patient 4: EDSS at biopsy 4.0, EDSS at last follow-up 3.5). Unfortunately, patient 5 deteriorated steadily even after biopsy and was discharged from hospital to a nursing home with an EDSS of 9.5 (EDSS at biopsy 5.5). Follow-up periods ranged between 6 and 27 months.

\section{PML patients without natalizumab treatment}

Four patients with low-inflammation PML not related to natalizumab were considered controls. Previous diseases were HIV in two cases, suspected mastocytosis or lymphoma, and CD4 T-cell deficiency of unknown etiology. Diagnosis was confirmed by IHC for JCV. Moreover, three cases of "inflammatory" PML, characterized by an unusually high inflammation, were included: (1) an HIV patient initially published by Vendrely et al. [25]; this patient developed an IRIS after PML and initiation of HAART therapy (HIV-PML-IRIS); (2) a 67 year-old male patient with rheumatoid arthritis as well as prostate cancer and preceding chemotherapy; (3) a 62 year-old female without previous illnesses. As there is currently no exact definition of inflammatory PML, we used this term for patients with more than $500 \mathrm{~T}$ cells $/ \mathrm{mm}^{2}$ within PML lesions.

\section{MS patients without PML}

$\mathrm{T}$ cell and plasma cell numbers for MS plaques were taken from the literature [13].

Histopathology

\section{Immunohistochemistry}

Specimens were fixed in $4 \%$ paraformaldehyde and embedded in paraffin. Slices $4 \mu \mathrm{m}$ thick were stained with hematoxylin and eosin (HE), Luxol fast blue/periodic acidSchiff (LFB/PAS), and Bielschowsky's silver impregnation. Immunohistochemical staining was performed with a biotin-avidin technique. The following primary antibodies were used: anti-CD3 (clone CD3-12, Serotec, UK), antiCD8 (clone C8/144B, Dako, Denmark), anti-CD20 (clone L26, Dako, Denmark), anti-CD138 (clone M/15, Dako, Denmark), and for JCV detection anti-SV40 (clone PAb416, Merck, Germany) and PAb 2003 (kindly provided by Dr. R. J. Frisque, Pennsylvania State University, USA) [16].

In situ hybridization

A JCV biotinylated probe corresponding to the entire JCV genome was used for DNA-DNA ISH (Enzo Diagnostics, Farmingdale, NY, USA).

Morphometry

The number of inflammatory cells and virally infected cells (PAb2003) was counted in at least ten standardized microscopic fields each of size $0.0625 \mathrm{~mm}^{2}$, defined by an ocular morphometric grid. Demyelinated areas as well as nondemyelinated white and grey matter were counted separately. In the text and figures, the median number of positive cells $/ \mathrm{mm}^{2}$ is given.

\section{Statistics}

The nonparametric Spearman rank correlation test was performed. Tests were classified as significant if the $p$ value was $<0.05$ (GraphPad Software, Inc., San Diego, CA, USA).

\section{MRI}

Routine brain MRI using 1.5 or $3.0 \mathrm{~T}$ machines with the standard protocol for MS was performed for the five biopsied patients and consisted of the following scans: axial dual fast spin-echo T2/proton density-weighted images, spin echo T1-weighted images with and without gadolinium contrast, and fluid inversion recovery (FLAIR) scans. Acquisition parameters were not exactly the same in all cases, as scans were performed in different centers. All images were reviewed at the same reading center by expert neuroradiologists (EWR, MAS).

\section{Results}

An extensive, CD8-dominated T cell infiltrate was found in natalizumab-associated PML, indicative of immune reconstitution inflammatory syndrome

Four out of the five analyzed biopsy cases showed a pronounced inflammatory infiltrate. Of these, three patients 


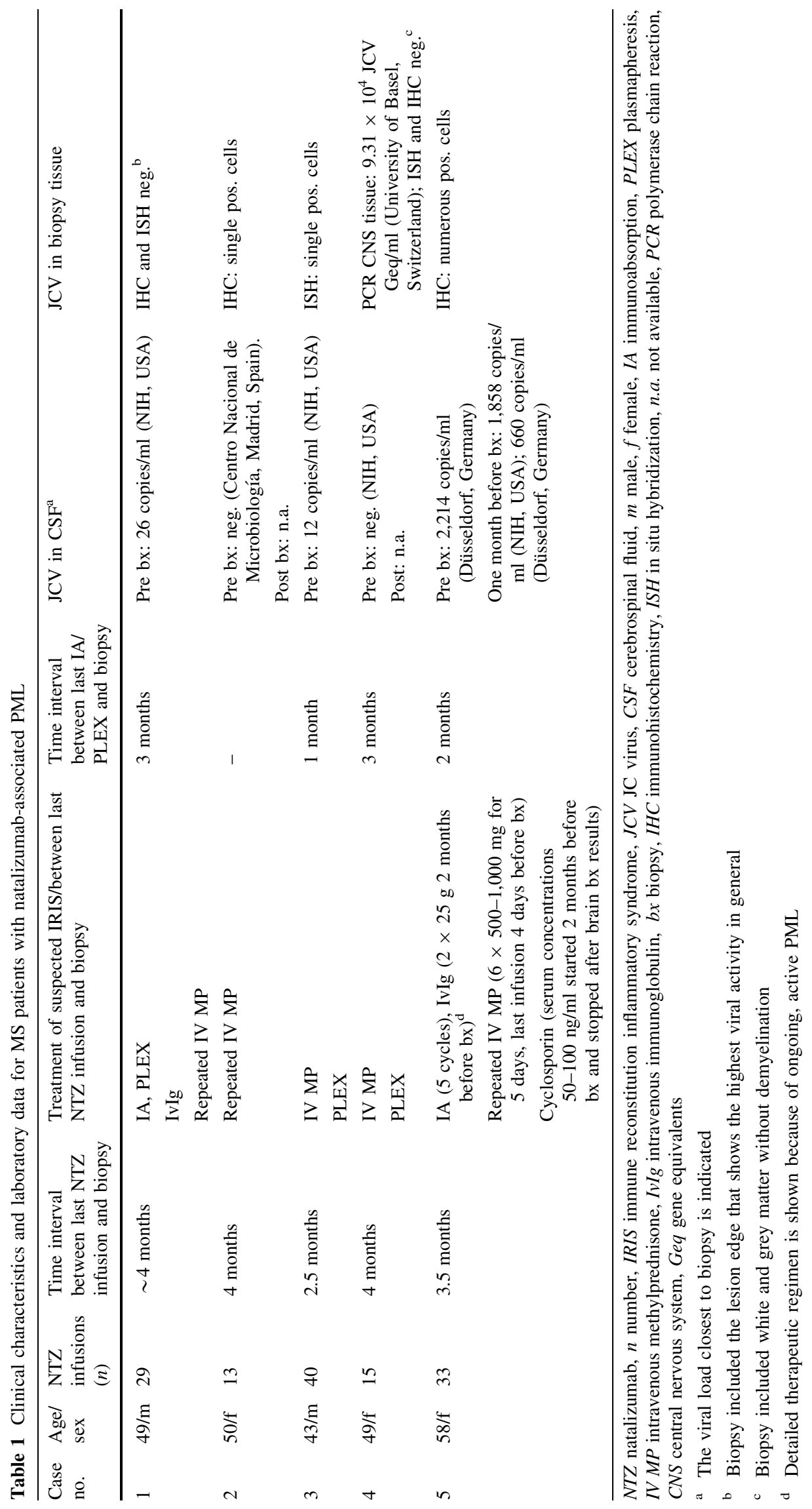


Fig. 1 Histology of IRIS is characterized by extensive T-cell inflammation in natalizumab-associated PML. An inflammatory demyelinating lesion with pronounced inflammation is shown (a H\&E, b LFB/PAS). T cells are dominated by $\mathrm{CD} 8+\mathrm{T}$ cells (c CD3, d CD8). Inflammation is also evident in adjacent nondemyelinated white and grey matter $(\mathbf{e}+\mathbf{f} \mathrm{CD} 3)$. Original magnifications: $\mathbf{a}+\mathbf{b} \times 40 ; \mathbf{c}-\mathbf{f} \times 100$. Scale bars $200 \mu \mathrm{m}$. Patient 2

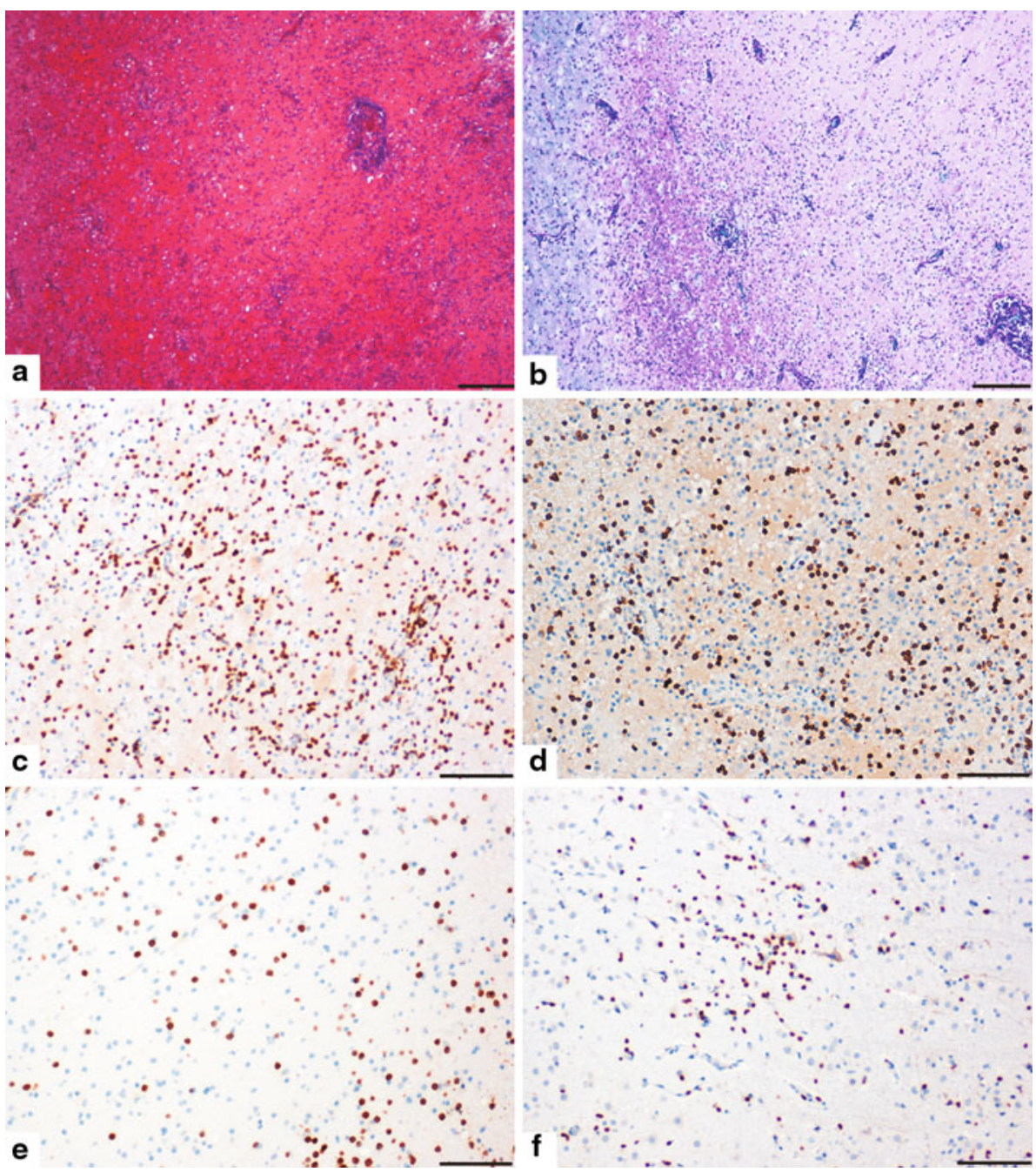

MRI characteristics in natalizumab-associated PML cases were compatible with IRIS

All patients showed T2 and FLAIR lesions characteristic of MS that were nonenhancing after gadolinium application. Moreover, all patients showed lesions compatible with PML at the time point of first PML symptoms. These lesions were enlarged and showed new or pronounced gadolinium enhancement at biopsy 2.5-4 months later, characterized as follows.

Patient 1 showed bilateral occipital, diffuse abnormalities with little mass effect and fuzzy borders (Fig. 3a). T1 post-contrast images revealed hypointense lesions with faint linear peripheral enhancement surrounding the lesions (Fig. 3b, arrows).

Patient 2 revealed a large frontoparietal hyperintense area with typical destruction of $U$ fibers almost exclusively confined to the white matter (Fig. 3c). The lesion was hypointense in postcontrast T1-weighted images, with some tiny, speckled enhancement at the lesion edge without any mass effect (Fig. 3d, arrow). 


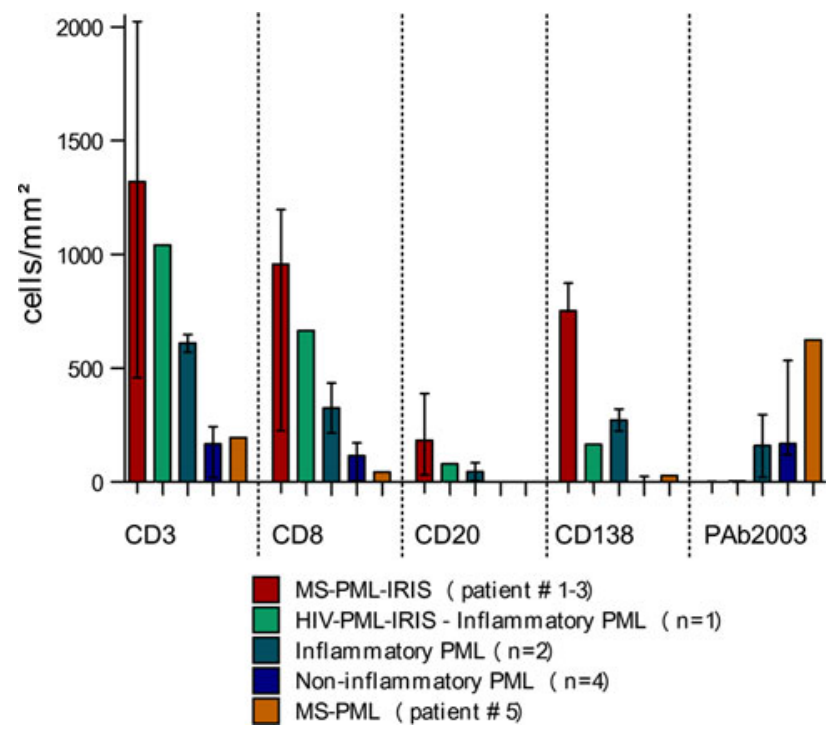

Fig. 2 Quantification of inflammation and virally infected cells within demyelinating lesions in MS-PML-IRIS, ongoing MS-PML, and non-MS PML. Numbers of T cells (CD3), CD8+ T cells (CD8), $B$ cells (CD20), plasma cells (CD138), and virally infected cells (PAb2003) were analyzed within demyelinating lesions in MS-PMLIRIS, ongoing MS-PML, and control groups. The median and range are indicated

An extensive lesion involving mainly the frontoparietal region was observed in case \#3 (Fig. 3e). The pattern of enhancement in this case differed, as it showed intense enhancement at the medial border and inside the lesion (Fig. 3f, arrows), suggesting a diagnosis of IRIS.

A large, diffuse lesion in the parietooccipital area with tiny, speckled enhancement within the lesion and linear enhancement at the lesion edge was seen in patient \#4 (not shown).

The fifth patient with histologically confirmed, active PML displayed multiple lesions, with the biopsied lesion revealing linear and irregular gadolinium enhancement at the lesion edge. Other lesions showed diffuse and speckled enhancement within lesions (Fig. 4a, b).

In conclusion, MRI in patients with pronounced inflammation shows different enhancement patterns with (a) faint enhancement, located mainly in the periphery of PML lesions (Fig. 3b), (b) linear and speckled enhancement at the grey and white matter junction or within the grey matter (Fig. 3d), and (c) intense focal or linear enhancement inside PML lesions and in the periphery (Fig. 3f). These characteristics are compatible with IRIS [2]. However, as the fifth patient also showed MRI characteristics compatible with PML-IRIS, MRI did not allow a clear differentiation between PML and IRIS and active PML.

Taking the histological and MRI results together, we assume that the four analyzed cases with pronounced inflammation (patients \#1-4) represent the histopathology of IRIS in natalizumab-associated PML (called MS-PMLIRIS from here on).

MS-PML-IRIS showed pronounced T cell inflammation compared with non-MS PML and multiple sclerosis

In MS-PML-IRIS, the numbers of CD3-positive T cells as well as CD8-positive T cells were approximately eight times higher than in patients with PML not related to natalizumab therapy (Fig. 2). Patients with inflammatory PML showed high numbers of $\mathrm{T}$ cells, with the median reaching about two-thirds of MS-PML-IRIS (Fig. 2). Comparing single patients, case 3, with natalizumab-associated PML and IRIS, showed a lower T-cell infiltrate (CD3+ T cells: 435 cells $/ \mathrm{mm}^{2}$ ) compared to the HIV-PML-IRIS patient (853 cells $/ \mathrm{mm}^{2}$ ), indicating an overlap of MS-PML-IRIS and inflammatory PML with respect to the T-cell inflammation. Inflammatory cells were found in PML controls in grey and nondemyelinating white matter as well (data not shown).

T-cell numbers were compared with data from actively demyelinating MS lesions from the literature [13]. T-cell numbers in MS-PML-IRIS were nine times higher than in MS controls, taking the published number of approximately 150 cells $/ \mathrm{mm}^{2}$.

Outstandingly high numbers of plasma cells in MS-PML-IRIS were evident

Strikingly high numbers of plasma cells were found in lesions from patients with MS-PML-IRIS (Figs. 2, 5a). The median was 752 plasma cells $/ \mathrm{mm}^{2}$; thus, every third inflammatory cell within the lesion represented a plasma cell. Plasma cells were evenly distributed within the parenchyma. B cells were found predominantly in perivascular spaces and in lower numbers (Fig. 2). Plasma cells were also present in nondemyelinated white and grey matter (WM: 156 cells $/ \mathrm{mm}^{2}$, GM: 41 cells $/ \mathrm{mm}^{2}$; Fig. $5 \mathrm{c}, \mathrm{d}$ ).

In contrast, no plasma cells and B cells were found in low-inflammatory PML not related to natalizumab therapy. Inflammatory PML lesions showed 242 plasma cells $/ \mathrm{mm}^{2}$; thus, approximately every fifth inflammatory cell represented a plasma cell (Figs. 2, 5b). Comparing single patients, plasma cells showed consistently higher values in MS-PML-IRIS (lowest value 751 plasma cells $/ \mathrm{mm}^{2}$ ) compared to non-MS PML cases (highest value 320 plasma cells $/ \mathrm{mm}^{2}$ ).

In MS biopsies, approximately six plasma cells $/ \mathrm{mm}^{2}$ were found within lesions [13]. Thus, plasma cell numbers in MS-PML-IRIS were approximately 125 times higher than in MS plaques. 
Fig. 3 MRI characteristics of patients with natalizumabassociated PML and

histologically confirmed IRIS.

Axial FLAIR images $(\mathbf{a}, \mathbf{c}, \mathbf{e})$ of MS patients, cases 1, 2, and 3, with corresponding contrastenhanced T1-weighted images $(\mathbf{b}, \mathbf{d}, \mathbf{f})$ are shown. Different patterns of enhancement in IRIS can be seen, ranging from faint peripheral enhancement to intense enhancement of the lesions (open arrows in $\mathbf{b}, \mathbf{d}$, and $\mathbf{f}$ ). The area of biopsy is indicated (closed arrows in a, c, and $\mathbf{e})$

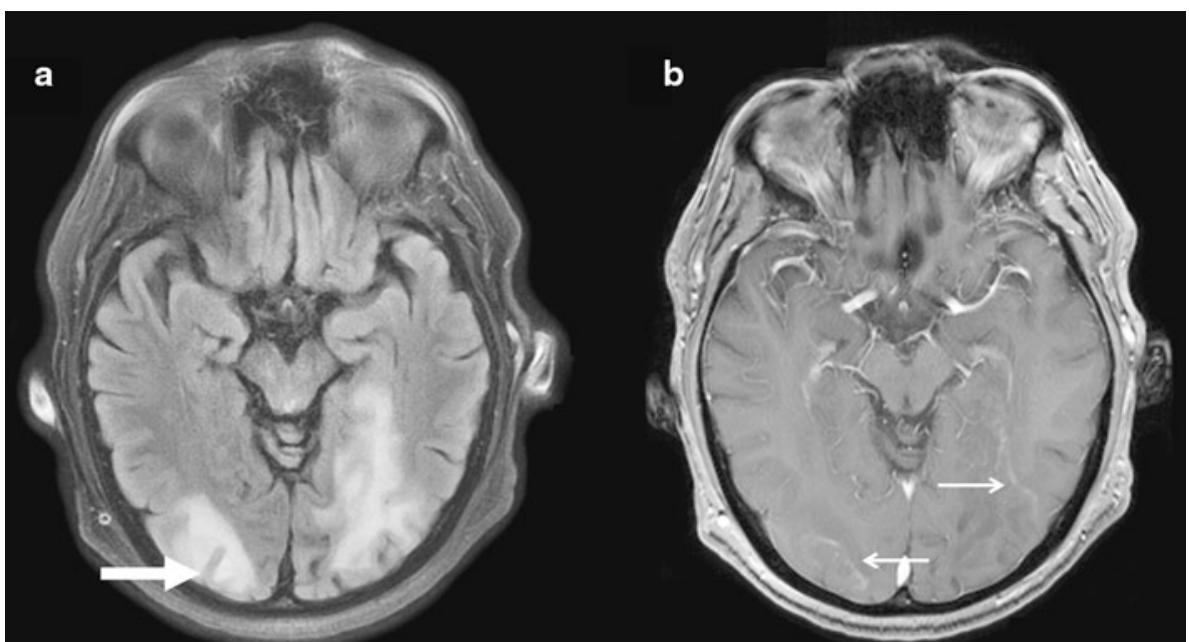

Patient \# 1
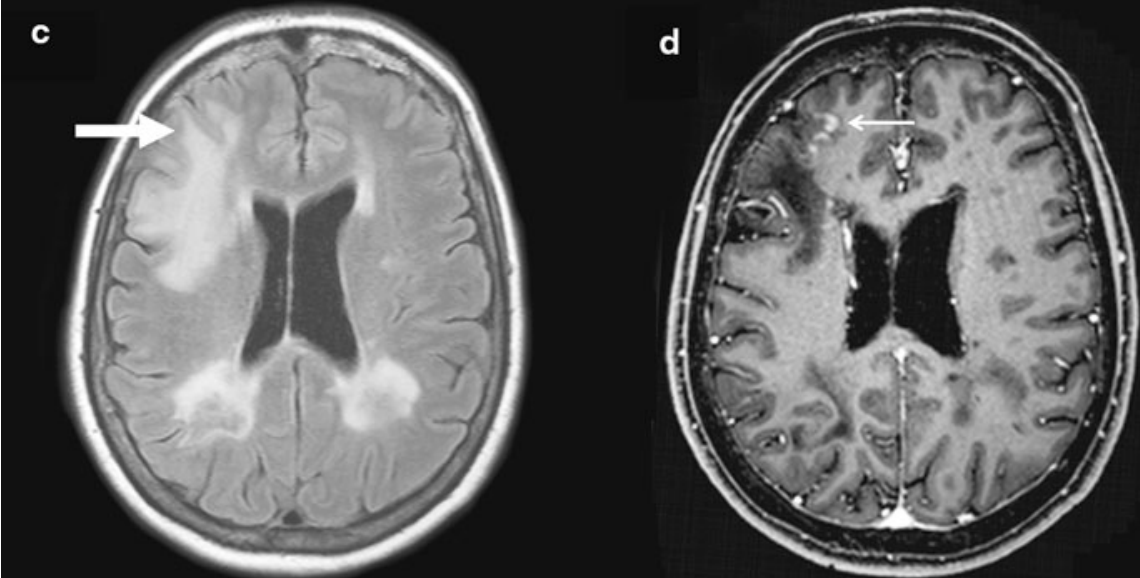

Patient \# 2

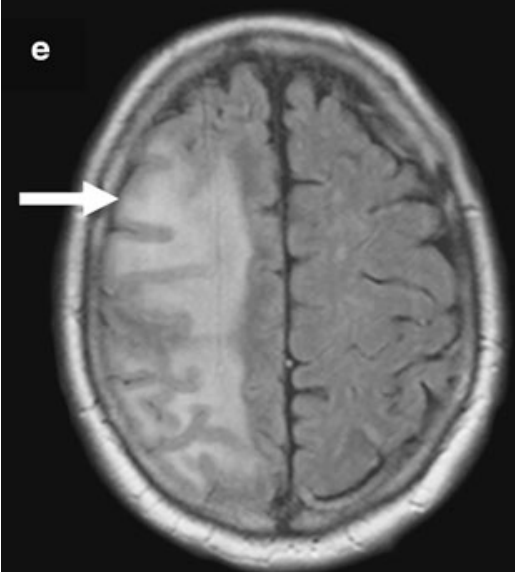

f

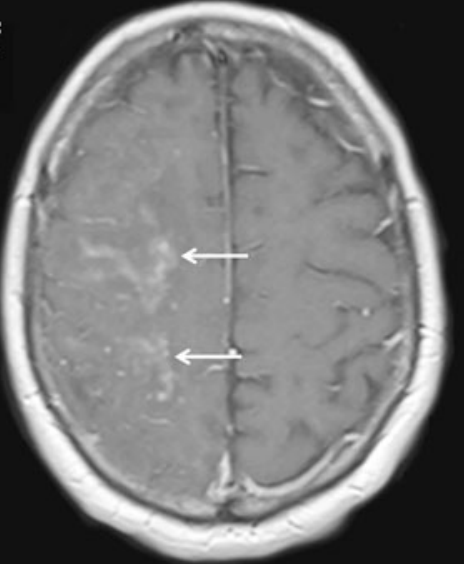

Patient \# 3 
Fig. 4 MRI characteristics of a patient with histologically confirmed active natalizumabassociated PML. Axial FLAIR (a) and corresponding contrastenhanced T1-weighted images (b) are shown (case 5). Linear enhancement at the lesion edge as well as diffuse and speckled enhancement within lesions are found (open arrows in b). The enhancement pattern does not allow differentiation between active PML and IRIS. The biopsied area is indicated (closed arrow in a)

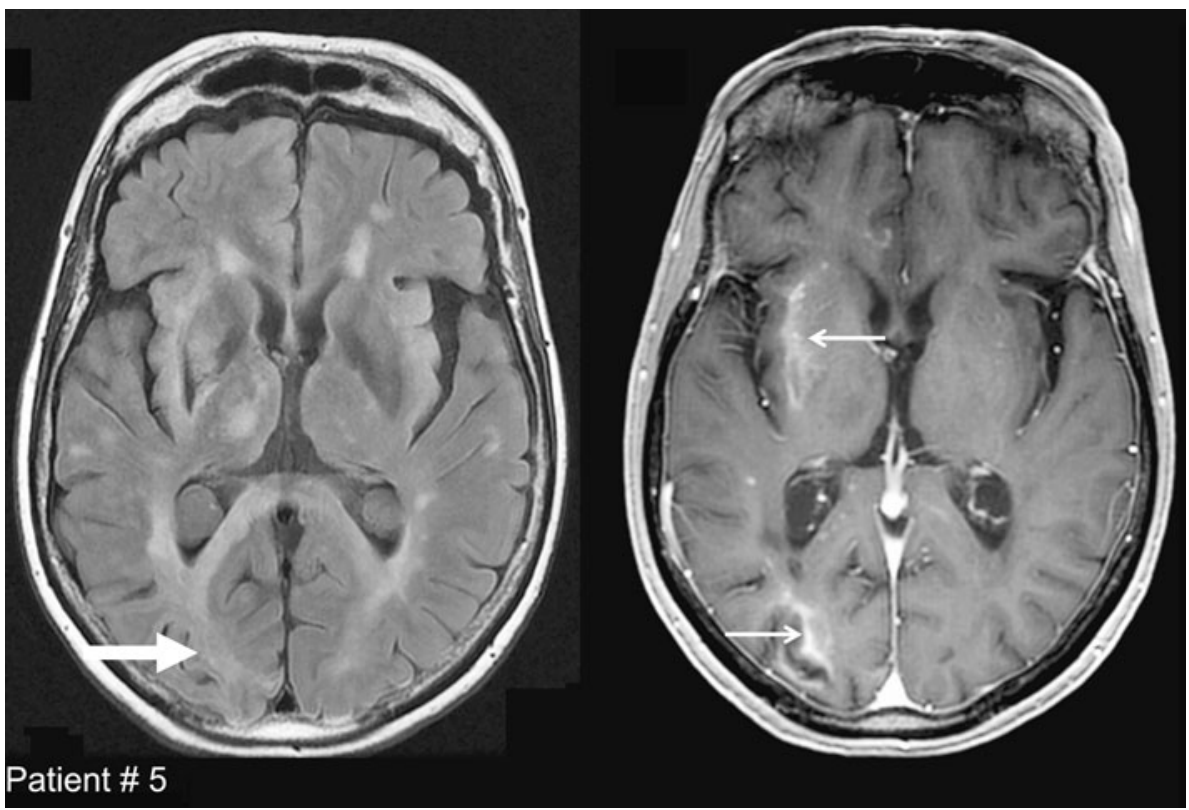

Fig. 5 High numbers of plasma cells are evident in natalizumabassociated PML with IRIS. Strikingly high numbers of plasma cells are found in MSPML-IRIS lesions (a). Lower numbers are present in inflammatory PML cases (b). In MS-PML-IRIS, plasma cells are also evident in nondemyelinated white and grey matter (c, d) (a-d CD138). Original magnifications:

a-d $\times 100$. Scale bars $200 \mu \mathrm{m}$. $\mathbf{a}+\mathbf{d}$ Patient $2, \mathbf{b}$ inflammatory PML control, c patient 1

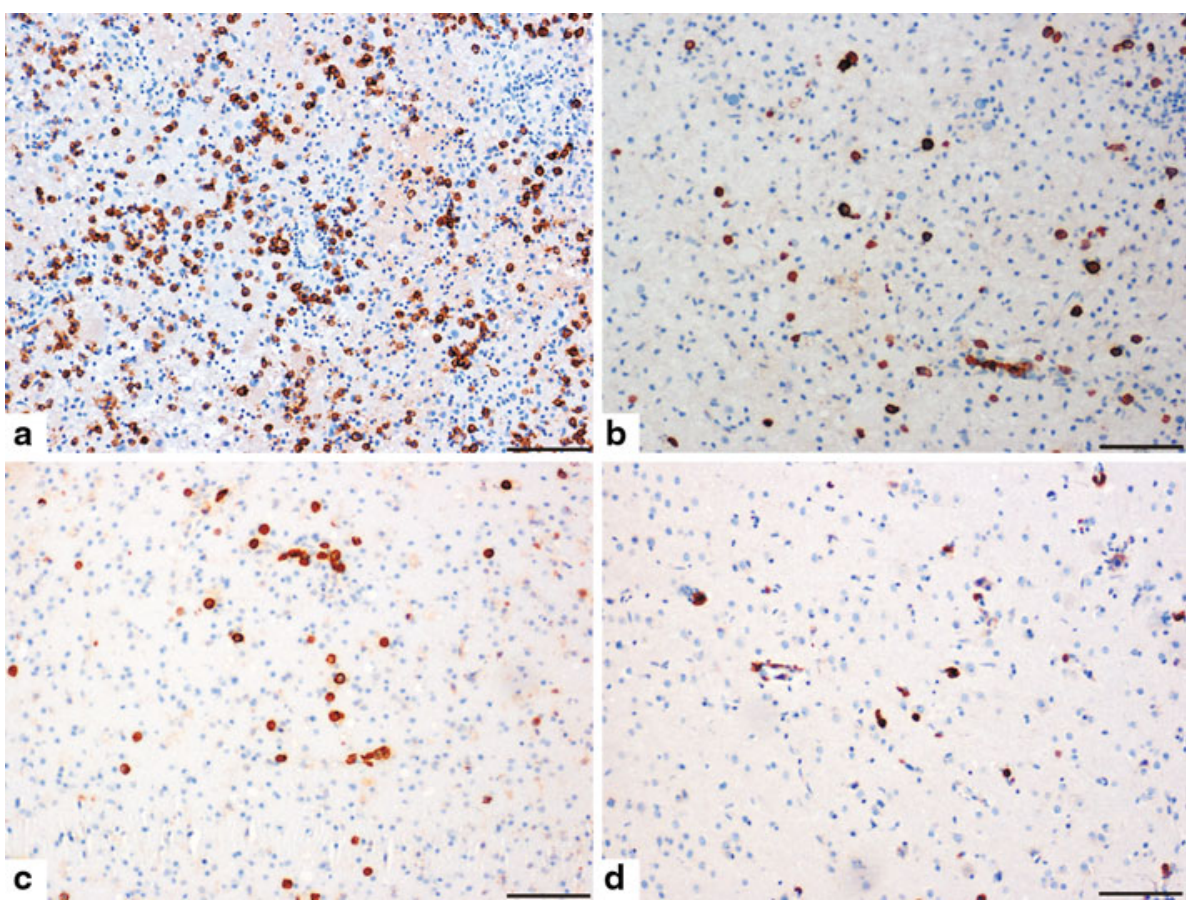

MS-PML-IRIS showed no or low numbers of virally infected cells

Single cells positive for JCV-DNA or protein were found in two cases with MS-PML-IRIS (Fig. 2). Typical ground glass oligodendrocytes at the lesion edge were not found.

In non-MS PML, virally infected cells were detected in high numbers in lesions (Fig. 2), as well as in nondemyelinated grey matter (45 PAb2003 + cells $/ \mathrm{mm}^{2}$, three cases) and white matter (56 PAb2003 + cells $/ \mathrm{mm}^{2}$, two cases).

The inflammation correlated negatively with the number of virally infected cells. This holds true for CD3 $+\mathrm{T}$ cells
(Spearman $r=-0.46, p=0.03), \mathrm{CD} 8+\mathrm{T}$ cells $(r=$ $-0.53, p=0.01)$, plasma cells $(r=-0.45, p=0.04)$, and B cells $(r=-0.43, p=0.048)$.

\section{Discussion}

We describe in detail the histopathological features and MRI correlates in five MS patients following natalizumabassociated PML.

Our study was limited by the amount of tissue available for investigations and the small number of patients 
investigated. Additionally, the different time frames between the end of natalizumab treatment, diagnosis of PML, CSF tests, and IRIS may affect the pathology of the lesions, and must be taken into account when interpreting the data. Nevertheless, the homogeneous pathology in four out of five cases presented here gives a comprehensive picture of MS-PML-IRIS.

Histology reveals strikingly pronounced inflammation and no or only low numbers of virally infected cells in four out of five patients, indicating a strong immune response. The inflammation is dominated by $\mathrm{CD} 8+\mathrm{T}$ cells; the abundance of plasma cells is remarkable. MRI shows enlarging and gadolinium-enhancing lesions, compatible with IRIS [2]. Thus, we interpret the histopathology demonstrated here as PML-associated IRIS, as known from HIV-associated PML [15, 19, 25]. However, inflammation in our study is even more pronounced than in HIV-PMLIRIS. This might be explained by the effectively reconstituted (and in MS patients otherwise intact) immune system after the withdrawal of natalizumab. MS-PML-IRIS was detectable in our analyzed patients even three months after PLEX/IA, and also occurred in patient 2, who had received neither of these therapies. IRIS typically occurs about 2-5 weeks after PLEX, necessitates repeated courses of intravenous steroids (suggesting that IRIS persists for several months), and has been described as occurring without PLEX/IA three months after the withdrawal of natalizumab [2, 23].

CD8+ cytotoxic lymphocytes (CTLs) are known to be the main effector cell in viral infection [6]. In PML, an association between JC virus-specific CTLs and early control of the disease was shown [3]. Moreover, CD4+ cells seem to play a critical role in viral defense. The occurrence of PML in HIV patients with low CD4 counts might be taken as an argument. JCV-specific CD4+ T-cell responses are found in PML survivors, but not in patients with active PML [5].

A striking observation in our cases was the high number of plasma cells in MS-PML-IRIS. Interestingly, natalizumab treatment increases circulating pre-B and B cells in MS patients [10]. The mobilization of JCV carrying pre-B cells from the bone marrow may play a role in natalizumabassociated PML pathogenesis [14]. The role of plasma cells for viral defense in PML is debated. On the one hand, as PML develops despite the presence of JCV-specific immunoglobulin $\mathrm{G}(\operatorname{IgG})$, the humoral immune response seems incapable of preventing PML [9]. An intrathecal synthesis of IgG-antibodies directed against the JCV viral protein 1 (VP1) is found in $76 \%$ of PML patients, but is not correlated with clinical outcome [26]. On the other hand, a strong correlation between the plasma cell count in brain tissue and the humoral intrathecal immune response to the VP1 was found, suggesting a role for B cells/plasma cells and JCV antibodies in PML [26]. Inflammatory PML with extensive mononuclear inflammatory infiltrates, including numerous plasma cells, was associated with a less severe neurologic illness [18]. Finally, PML survivors also showed significant increases in JCV-specific $\mathrm{IgG}$ responses [7].

In summary, a specific cellular as well as humoral immune response seems to be relevant for viral defense. In our study, CD3- and CD8-positive T cells, B cells, as well as plasma cells were negatively correlated with the number of virally infected cells, underlining their potential role in PML infection. We find higher plasma cell numbers in MS-PML-IRIS patients than in non-MS inflammatory PML cases, even when T-cell numbers are similar. Thus, we cannot rule out the idea that a least part of the plasma cell population is pre-existent and related to the natalizumab treatment.

The clinician who cares for an MS patient with PML who is deteriorating clinically and radiologically after stopping natalizumab therapy is faced with the differential diagnosis of PML-IRIS, ongoing PML, and MS exacerbation. Histologically, in MS exacerbation, actively demyelinating lesions that are otherwise typical of MS are expected [12]. MRI is expected to show either homogeneously or ring-shaped enhancing lesions in typical periventricular or subcortical localizations. The histological characteristics of MS-PML-IRIS are clearly different from typical PML, as found in our fifth patient with natalizumab-associated PML. This patient was treated with immunosuppressive therapy before biopsy to combat IRIS. This case demonstrates the difficulty involved in finding the balance between suppressing clinical deterioration due to PML-IRIS, which may even lead to death, and halting the progression of PML [2]. Our patient with active PML (patient 5) showed higher viral gene copies than the patients with PML-IRIS histopathology (see Table 1). However, paraclinical parameters such as CSF JC virus load and peripheral CD4/CD8 cell counts do not help the clinician, as increasing viral titers as well as normal CD4/ CD8 ratios can be found in both PML-IRIS and active PML [2]. JC viral load is increased by greater than tenfold in MS patients with PML-IRIS and early MRI gadolinium enhancement [23]. Although it seems unlikely, we cannot rule out that our patient with active PML showed IRIS histopathology in nonbiopsied lesions. MRI shows enlarging and gadolinium-enhancing lesions in both conditions. Contrast enhancement is a nonspecific sign of an impaired blood-brain barrier and can be seen with different patterns in inflammatory conditions of the brain. So far, it has not appeared possible to distinguish MS-PML-IRIS from ongoing PML in MS patients using only imaging data. However, PML lesions tend to show faint enhancement in the periphery of the lesion. More cases with 
confirmed pathology are needed to identify MRI patterns that differentiate these two entities.

In order to clarify the immunopathogenesis of MSPML-IRIS, further investigations should focus on the role of plasma cells in JCV infection, as well as the effect of natalizumab on immune surveillance and inflammation within the CNS.

In summary, we report IRIS histopathology in four MS patients with natalizumab-associated PML. Histopathology is characterized by a pronounced inflammatory infiltrate with a predominance of CD8 $+\mathrm{T}$ cells and high numbers of plasma cells within lesions as well as adjacent grey and white matter. A biopsy was helpful in our cases to either establish the diagnosis of PML infection or to differentiate between ongoing PML, MS-PML-IRIS, and MS exacerbation. This guided the clinician to either stop medication (steroids, immunosuppressive therapy) in active PML or to further suppress inflammation with steroids in MS-PML-IRIS.

Acknowledgments This work was supported by grants from the Heidenreich von Siebold Program of the University Medical Center Göttingen (I.M.) and the German Ministry for Education and Research (BMBF, "German Competence Network Multiple Sclerosis" (KKNMS), UNDERSTANDMS, 01GI0910) (W.B. and H.W.). We thank Jasmin Held and Sven Müller for expert technical assistance.

Open Access This article is distributed under the terms of the Creative Commons Attribution Noncommercial License which permits any noncommercial use, distribution, and reproduction in any medium, provided the original author(s) and source are credited.

\section{References}

1. Berger JR (2010) Progressive multifocal leucoencephalopathy and newer biological agents. Drug Saf 33:969-983

2. Clifford DB, De LA, Simpson DM, Arendt G, Giovannoni G, Nath A (2010) Natalizumab-associated progressive multifocal leukoencephalopathy in patients with multiple sclerosis: lessons from 28 cases. Lancet Neurol 9:438-446

3. Du Pasquier RA, Kuroda MJ, Zheng Y, Jean-Jacques J, Letvin NL, Koralnik IJ (2004) A prospective study demonstrates an association between JC virus-specific cytotoxic T lymphocytes and the early control of progressive multifocal leukoencephalopathy. Brain 127:1970-1978

4. Engelhardt B, Kappos L (2008) Natalizumab: targeting alpha4integrins in multiple sclerosis. Neurodegener Dis 5:16-22

5. Gasnault J, Kahraman M, de Herve MG, Durali D, Delfraissy JF, Taoufik Y (2003) Critical role of JC virus-specific CD4 T-cell responses in preventing progressive multifocal leukoencephalopathy. AIDS 17:1443-1449

6. Kalams SA, Walker BD (1998) The critical need for CD4 help in maintaining effective cytotoxic T lymphocyte responses. J Exp Med 188:2199-2204

7. Khanna N, Wolbers M, Mueller NJ, Garzoni C, Du Pasquier RA, Fux CA, Vernazza P, Bernasconi E, Viscidi R, Battegay M, Hirsch HH (2009) JC virus-specific immune responses in human immunodeficiency virus type 1 patients with progressive multifocal leukoencephalopathy. J Virol 83:4404-4411
8. Khatri BO, Man S, Giovannoni G, Koo AP, Lee J-C, Tucky B, Lyon G, Jurgensen S, Woodworth J, Goelz S, Duda PW, Panzara MA, Ransohoff RM, Fox RJ (2009) Effect of plasma exchange in accelerating natalizumab clearance and restoring leukocyte function. Neurology 72:402-409

9. Koralnik IJ, Du Pasquier RA, Letvin NL (2001) JC virus-specific cytotoxic $\mathrm{T}$ lymphocytes in individuals with progressive multifocal leukoencephalopathy. J Virol 75:3483-3487

10. Krumbholz M, Meinl I, Kumpfel T, Hohlfeld R, Meinl E (2008) Natalizumab disproportionately increases circulating pre-B and B cells in multiple sclerosis. Neurology 71:1350-1354

11. Kuhle J, Gosert R, Bühler R, Derfuss T, Sutter R, Yaldizli Ö, Radue E-W, Ryschkewitsch C, Major EO, Kappos L, Frank S, Hirsch HH (2011) Management and outcome of CSF-JC virus PCR-negative PML in a natalizumab-treated MS patient. Neurology (in press)

12. Lenhard T, Biller A, Mueller W, Metz I, Schonberger J, Wildemann B (2010) Immune reconstitution inflammatory syndrome after withdrawal of natalizumab? Neurology 75:831-833

13. Lucchinetti C, Brück W, Parisi J, Scheithauer B, Rodriguez M, Lassmann H (2000) Heterogeneity of multiple sclerosis lesions: implications for the pathogenesis of demyelination. Ann Neurol 47:707-717

14. Major EO (2009) Reemergence of PML in natalizumab-treated patients-new cases, same concerns. N Engl J Med 361: 1041-1043

15. Miralles P, Berenguer J, Lacruz C, Cosin J, Lopez JC, Padilla B, Munoz L, Garcia-de-Viedma D (2001) Inflammatory reactions in progressive multifocal leukoencephalopathy after highly active antiretroviral therapy. AIDS 15:1900-1902

16. Munoz-Marmol AM, Mola G, Fernandez-Vasalo A, Vela E, Mate JL, Ariza A (2004) JC virus early protein detection by immunohistochemistry in progressive multifocal leukoencephalopathy: a comparative study with in situ hybridization and polymerase chain reaction. J Neuropathol Exp Neurol 63:1124-1130

17. Polman $\mathrm{CH}, \mathrm{O}^{` C}$ Connor PW, Havrdova E, Hutchinson M, Kappos L, Miller DH, Phillips JT, Lublin FD, Giovannoni G, Wajgt A, Toal M, Lynn F, Panzara MA, Sandrock AW (2006) A randomized, placebo-controlled trial of natalizumab for relapsing multiple sclerosis. N Engl J Med 354:899-910

18. Richardson EP Jr, Johnson PC (1975) Atypical progressive multifocal leukoencephalopathy with plasma-cell infiltrates. Acta Neuropathol Suppl 6:247-250

19. Safdar A, Rubocki RJ, Horvath JA, Narayan KK, Waldron RL (2002) Fatal immune restoration disease in human immunodeficiency virus type 1 -infected patients with progressive multifocal leukoencephalopathy: impact of antiretroviral therapy-associated immune reconstitution. Clin Infect Dis 35:1250-1257

20. Sandrock A et al (2011) American Academy of Neurology Annual Meeting 2011, Poster-AAN B03.248, Honolulu, Hawai, 21-28 April 2011

21. Schwab N, Hohn KG, Schneider-Hohendorf T, Metz I, Stenner MP, Jilek S, Du Pasquier RA, Gold R, Meuth SG, Ransohoff RM, Bruck W, Wiendl H (2011) Immunological and clinical consequences of treating a patient with natalizumab. Mult Scler (in press)

22. Shah R, Bag AK, Chapman PR, Cure JK (2010) Imaging manifestations of progressive multifocal leukoencephalopathy. Clin Radiol 65:431-439

23. Tan IL, McArthur JC, Clifford DB, Major EO, Nath A (2011) Immune reconstitution inflammatory syndrome in natalizumabassociated PML. Neurology 77:1061-1067

24. Tysabri (2011) Corporate website. http://tysabri.de/index.php? inhalt=tysabri.pmlinzidenz

25. Vendrely A, Bienvenu B, Gasnault J, Thiebault JB, Salmon D, Gray F (2005) Fulminant inflammatory leukoencephalopathy 
associated with HAART-induced immune restoration in AIDSrelated progressive multifocal leukoencephalopathy. Acta Neuropathol 109:449-455

26. Weber T, Trebst C, Frye S, Cinque P, Vago L, Sindic CJ, SchulzSchaeffer WJ, Kretzschmar HA, Enzensberger W, Hunsmann G, Luke W (1997) Analysis of the systemic and intrathecal humoral immune response in progressive multifocal leukoencephalopathy. J Infect Dis 176:250-254

27. Wenning W, Haghikia A, Laubenberger J, Clifford DB, Behrens PF, Chan A, Gold R (2009) Treatment of progressive multifocal leukoencephalopathy associated with natalizumab. N Engl J Med 361:1075-1080

28. Yousry TA, Major EO, Ryschkewitsch C, Fahle G, Fischer S, Hou J, Curfman B, Miszkiel K, Mueller-Lenke N, Sanchez E, Barkhof F, Radue EW, Jager HR, Clifford DB (2006) Evaluation of patients treated with natalizumab for progressive multifocal leukoencephalopathy. N Engl J Med 354:924-933 